\title{
Peptic Ulcer Disease and Misuses of Ulcer Healing Drugs in a Tertiary Care Hospital in Dhaka City
}

\author{
MD. HAFIZSARDAR, ${ }^{1}$ MOHAMMAD MURAD HOSSAI N ${ }^{2}$ KHAN ABUL KALAM AZAD, ${ }^{3}$ MD. UZZWAL MALLIK ${ }^{4}$ \\ MOUMITA CHAKRABORTY 5
}

\begin{abstract}
:
This prospective cross sectional study was conducted in Dhaka Medical College Hospital, Dhaka during July, 20 I 3 to December, 2013. Hundred patients were included in this study. Peptic ulcer disease, presented as upper abdominal pain is one of the common disease with a number of underlying causes. Prospective analyses of 100 patients with upper abdominal pain were studied at medicine units of Dhaka Medical College Hospital, Dhaka. Of these 36 patients belonged to peptic ulcer, 20 patients to irritable bowel syndrome and 22 patients to non-ulcer dyspepsia. Next in order were helminthiasis (5 patients), cholelithiasis (4 patients), gastric carcinoma (4 patients), liver abscess (5 patients) chronic pancreatitis (3 patients) and acute pancreatitis (I patient). Mean age incidence in this series was 39.47 years. Male and female ratio was I.54:I. Forty patients were smoker with male and female ratio of 3.44: I.All patients had presenting feature of upper abdominal pain. Commonest site of pain was in the epigastrium in $48.08 \%$ of cases. Pain was burning in $43.27 \%$ cases, periodic pain in $24.03 \%$, and nocturnal hunger pain in $33.65 \%$ of cases. Relief of pain after taking food were observed in $38.46 \%$. Epigastric tenderness was present in $56.73 \%$ patients. The diagnosis of peptic ulcer disease, irritable bowel syndrome and non-ulcer dyspepsia, the three leading causes of upper abdominal pain, were suspected by history and physical examination but it was difficult to interpret these on clinical ground alone. Some routine and some selected investigation were done for confirmatory diagnosis.

In this series, significant disparity detected between clinically diagnosed peptic ulcer diseases $90.38 \%$ and endoscopically confirmed peptic ulcer disease, $34.62 \%$ cases. As a consequence of wrong diagnosis of PUD, there are huge misuses of ulcer healing drugs and a great economic burden on patients (300 taka per month) and on the nation.
\end{abstract}

Keywords: Peptic ulcer disease, misuse of drugs, ulcer healing drugs.

\section{Introduction:}

Upper abdominal pain is one of the common complaints of a number of underlying diseases. There are four types of abdominal pain: a) Visceral- Gut organs are sensitive to distention, contraction, torsion and stretching b) Parietalperitoneum is innervated by somatic nerve and its involvement by disease process e.g inflammation, infection and neoplasm causes sharp, well localized and lateralized pain c) Referred pain- e.g Gallbladder pain is referred to the back or shoulder tip and d) Psychogenic- depression or somatization disorder may be responsible for abdominal pain.

1. FCPS (Medicine), Associate Professor (Medicine), Dhaka Medical College.

2. FCPS (Medicine), Assistant Professor (Medicine), Dhaka Medical College.

3. FCPS (Medicine), MD, FACP, Professor (Medicine), Dhaka Medical College.

4. FCPS (Medicine), Lecturer, Forensic Medicine, Dhaka Medical College.

5. Resident, Department of Medicine, Dhaka Medical College.

Correspondence : Dr. Md. Hafiz Sardar, 42/A, Indira Road, FlatB4, Tejgaon, Dhaka. Cell: 01712269294, e-mail: drhafizsardar@ yahoo.com.
It may be asserted that majority of patients with upper abdominal pain do not have peptic ulcer. ${ }^{1}$ Functional gut disorders are common causes of upper abdominal pain. ${ }^{2} \mathrm{~A}$ hurried history taking and overemphasis upon physical signs will lead to erroneous inclusions of such cases in the category of peptic ulcer. ${ }^{3}$ A carefully taken history and its rational interpretation may help in diagnosis. Thus simple means like explanation, reassurance and dietary advices may save a lot of antacids, $\mathrm{H}_{2}$ blockers and proton pump inhibitors, in many cases.

\section{Materials and methods:}

All patients irrespective of age and sex presenting with upper abdominal pain in the twelve medicine units of Dhaka Medical College Hospital, Dhaka between July, 2013 and December, 2013 were considered for the study.The diagnostic criteria for a particular disease include its-symptoms, signs and results of investigations. History was taken carefully with particular emphasis on different characteristics of the upper abdominal pain. They were thoroughly examined. Investigations which were done routinely in all cases includes-complete blood counts, routine stool examination- 
physical and microscopic examination of three consecutive samples stool, including concentration technique for ova of helminthes, routine urinalysis, plain X-ray abdomen, endoscopy of the upper gastrointestinal tract, ultrasonography of the whole abdomen and chest radiograph. Selective investigations include- serum amylase, fasting blood sugar, ECG, ERCP, CT Scan of the abdomen and barium follow- through X-ray of small bowel. Relevant data were collected and enclosed into a preformed data collection sheet. The diagnosis of particular disease was made using the diagnostic criteria. Duodenal ulcer was diagnosed by the presence of abdominal pain of epigastric origin which was episodic, sharp, burning or gnawing in nature, hunger pain, nocturnal pain, periodic, associated with epigastric tenderness and endoscopically proved ulcer in the duodenum. Gastric ulcer was diagnosed by the presence of abdominal pain of epigastric origin, episodic, sharp or burning in character, pain precipitated by taking food, associated epigastric tenderness and endoscopically proved gastric ulcer. Non-ulcer dyspepsia ${ }^{4}$ was diagnosed by patients without peptic ulcer or any recognized anatomicopathological entity presented with periodic, postprandial epigastric pain that was typically relieved by food or antacids, or dysmotility- like dyspepsia characterized by abdominal distension, fullness, early satiety and/or nausea after meals. Diagnosis of Irritable bowel syndrome was made by the presence of abdominal distension, pain relief with bowel action, more frequent and looser stools with the onset of pain, mucorrhoea and sensation of incomplete evacuation following defecation. A subject with upper abdominal pain was put in this category only if the pain was at least partly but consistently relieved by clear bowel movement spontaneously or induced in patients with constipation by isphaghula husk or enema simplex. ${ }^{5}$ Helminthiasis was diagnosed by presence of ova or larvae of helminthes were found in stools and the upper abdominal pain were abolished or substantially reduced by anti-helminthic therapy. ${ }^{5}$ Diagnosis of cholelithiasis was made by ultrasonographic or ERCP finding of gallstone and small contracted gall bladder. Acute pancreatitis was diagnosed by high serum amylase and ultrasonographicfindings of acute pancreatitis. Chronic pancreatitis was diagnosed by ultrasonographic or ERCP features of chronic pancreatitis and/or radiological finding of pancreatic calcification.

Data were consolidated, grouped and analyzed.

\section{Results and observations:}

One hundred and four patients were included in the study.Out of total admitted patients, subjects presented with upper abdominal pain were 100 (2.19\%) in number, in whom 61(60.58\%) were male and 39 (39.42\%) were female patients. Male subjects were higher in number among the patients present with upper abdominal pain (M:F=1.56:1) (Table I).

Their age ranged between 18 and 70 years with a mean of 39.47 years (Table II). Out of 100 cases, majority were nonsmoker. Forty patients were smokers with a male and female ratio was (M: $\mathrm{F}=3.44: 1)$.

Among the male (61cases) patients, 22 were businessmen, 15 were day laborers, 6 were service-holders, 11 were farmers and 7 were students by profession. Among the female (39 case) patient majority were house wives (33 cases), 3 were service-holders and 3 were students by profession.

Table- I

Personal data of the patients $(n=100)$

\begin{tabular}{lccc}
\hline No. of Patients & Total & Male & Female \\
\hline Presented with upper abdominal pain & $100(100 \%)$ & $61(60.58 \%)$ & $39(39.42 \%)$ \\
Mean age in years & 39.47 & 41.57 & 35.52 \\
Organic disease & $54(54.81 \%)$ & $36(36.54 \%)$ & $18(18.27 \%)$ \\
Functional & $46(45.19 \%)$ & $25(24.04 \%)$ & $21(21.15 \%)$ \\
\hline
\end{tabular}

Table-II

Age distribution (years)

\begin{tabular}{|c|c|c|c|c|c|c|c|c|c|}
\hline $\begin{array}{l}\text { Age group } \\
\text { (years) }\end{array}$ & $\begin{array}{l}\text { PUD } \\
(\mathrm{n}=36)\end{array}$ & $\begin{array}{c}\text { IBS } \\
(n=24)\end{array}$ & $\begin{array}{l}\text { NUD } \\
(n=22)\end{array}$ & $\begin{array}{l}\text { Helminthiasis } \\
\qquad(\mathrm{n}=5)\end{array}$ & $\begin{array}{l}\text { Cholelithiasis } \\
\qquad(\mathrm{n}=4)\end{array}$ & $\begin{array}{c}\text { GC } \\
(n=4)\end{array}$ & $\begin{array}{c}\text { LA } \\
(n=5)\end{array}$ & $\begin{array}{c}\text { CP } \\
(n=3)\end{array}$ & $\begin{array}{l}\text { AP } \\
(n=1)\end{array}$ \\
\hline $18-30$ & 15 (44.44\%) & 14 (58.33\%) & $6(27.27 \%)$ & $1(20 \%)$ & - & & $2(50 \%)$ & 1 (33.33\%) & - \\
\hline $31-40$ & $10(27.78)$ & 8 (33.33\%) & 8 (36.36\%) & $3(60 \%)$ & $1(25 \%)$ & - & 1 (25\%) & $1(33.33 \%)$ & $1(100 \%)$ \\
\hline $41-50$ & $6(16.67)$ & $2(8.33 \%)$ & $6(22.73 \%)$ & - & $1(25 \%)$ & - & 1 (25\%) & (33.33\%) & - \\
\hline$>50$ & 5 (11.11\%) & - & 3 (13.64\%) & $1(20 \%)$ & $2(50 \%)$ & $4(100 \%)$ & - & - & - \\
\hline
\end{tabular}


Table-III

Causes of upper abdominal pain $(n=104)$

\begin{tabular}{|c|c|c|c|c|}
\hline Disease categories & Subcategories & No. of Patients & Male $(n=49)$ & Female $(\mathrm{n}=55)$ \\
\hline \multirow[t]{3}{*}{ Peptic ulcer disease } & Total & $36(34.62 \%)$ & $26(25 \%)$ & $10(9.62 \%)$ \\
\hline & DU & $26(72.22 \%)$ & $20(55.56 \%)$ & $6(16.66 \%)$ \\
\hline & GU & $10(27.78 \%)$ & $6(16.67 \%)$ & $4(11.11 \%)$ \\
\hline \multirow[t]{4}{*}{ Irritable bowel syndrome } & Total & $24(23.08 \%)$ & $15(14.42 \%)$ & $9(8.65 \%)$ \\
\hline & $* \operatorname{lBS}(\mathrm{C})$ & $15(62.5 \%)$ & 8(33.33\%) & $7(29.11 \%)$ \\
\hline & $* \operatorname{lBS}(\mathrm{A})$ & $7(29.17 \%)$ & $5(20.83 \%)$ & $2(8.33 \%)$ \\
\hline & $* \operatorname{lBS}(\mathrm{D})$ & $2(8.33 \%)$ & $0(0 \%)$ & $2(8.33 \%)$ \\
\hline \multirow[t]{3}{*}{ Non-ulcer dyspepsia } & Total & $22(21.15 \%)$ & $10(9.61 \%)$ & $12(11.54 \%)$ \\
\hline & Moynihan’s & $21(95.45 \%)$ & $10(45.45 \%)$ & $11(50 \%)$ \\
\hline & Dysmotility & $1(4.55 \%)$ & $0(0 \%)$ & $1(4.55 \%)$ \\
\hline Helminthiasis & & $5(4.81 \%)$ & $3(2.88 \%)$ & $2(1.92 \%)$ \\
\hline Cholelithiasis & & $4(3.85 \%)$ & $1(0.96 \%)$ & $3(2.88 \%)$ \\
\hline Gastric carcinoma & & $4(3.85 \%)$ & $3(2.88 \%)$ & $1(0.96 \%)$ \\
\hline Liver abscess & & $5(3.85 \%)$ & $4(2.88 \%)$ & $1(0.96 \%)$ \\
\hline Chronic pancreatitis & & $3(2.88 \%)$ & $1(0.96 \%)$ & $2(1.92 \%)$ \\
\hline Acute pancreatitis & & $1(0.96 \%)$ & $1(0.96 \%)$ & $2(1.92 \%)$ \\
\hline Unexplained & & $1(0.96 \%)$ & $0(0 \%)$ & $1(0.96 \%)$ \\
\hline
\end{tabular}

* IBS (C) Predominantly constipating * IBS (A) Diarrhoea alternating with constipation

* IBS (D) Predominantly diarrhoeal

Several quite different diseases could be distinguished in subjects presented with upper abdominal pain (Table III). Forty six (45.19\%) subjects had no organic disease, with a male and female ratio was 1.14:1. Peptic ulcer disease topped the list. Thirty six subjects (34.62\%) had peptic ulcer disease (PUD).Of them 26 cases (25\%) were male and 10 cases (9.62\%) were female. In this study male patients were more in number with male and female ratio was 2.6:1.

Out of 36cases of peptic ulcer, 26(72.22\%) were detected to have duodenal ulcer and 10(27.78\%) were gastric ulcer. Male and female ratio in duodenal and gastric ulcer was 3.33:1 and 1.5:1 respectively (Table-IV).The ratio between duodenal and gastric ulcer was 2.6:1.

Table-IV

Causes of upper abdominal pain $(n=104)$

\begin{tabular}{|c|c|c|c|c|}
\hline Disease categories & Subcategories & No. of Patients & Male $(n=49)$ & Female $(\mathrm{n}=55)$ \\
\hline \multirow[t]{3}{*}{ Peptic ulcer disease } & Total & $36(34.62 \%)$ & $26(25 \%)$ & $10(9.62 \%)$ \\
\hline & DU & 26(72.22\%) & $20(55.56 \%)$ & $6(16.66 \%)$ \\
\hline & GU & $10(27.78 \%)$ & $6(16.67 \%)$ & $4(11.11 \%)$ \\
\hline \multirow[t]{4}{*}{ Irritable bowel syndrome } & Total & $24(23.08 \%)$ & $15(14.42 \%)$ & $9(8.65 \%)$ \\
\hline & $* \operatorname{lBS}(\mathrm{C})$ & $15(62.5 \%)$ & 8(33.33\%) & 7(29.11\%) \\
\hline & $* \operatorname{lBS}(\mathrm{A})$ & $7(29.17 \%)$ & $5(20.83 \%)$ & $2(8.33 \%)$ \\
\hline & $* \operatorname{lBS}(\mathrm{D})$ & $2(8.33 \%)$ & $0(0 \%)$ & $2(8.33 \%)$ \\
\hline \multirow[t]{3}{*}{ Non-ulcer dyspepsia } & Total & $22(21.15 \%)$ & $10(9.61 \%)$ & $12(11.54 \%)$ \\
\hline & Moynihan's & 21(95.45\%) & $10(45.45 \%)$ & $11(50 \%)$ \\
\hline & Dysmotility & $1(4.55 \%)$ & $0(0 \%)$ & $1(4.55 \%)$ \\
\hline Helminthiasis & & $5(4.81 \%)$ & $3(2.88 \%)$ & $2(1.92 \%)$ \\
\hline Cholelithiasis & & $4(3.85 \%)$ & $1(0.96 \%)$ & $3(2.88 \%)$ \\
\hline Gastric carcinoma & & $4(3.85 \%)$ & $3(2.88 \%)$ & $1(0.96 \%)$ \\
\hline Liver abscess & & $5(3.85 \%)$ & $4(2.88 \%)$ & $1(0.96 \%)$ \\
\hline Chronic pancreatitis & & $3(2.88 \%)$ & $1(0.96 \%)$ & $2(1.92 \%)$ \\
\hline Acute pancreatitis & & $1(0.96 \%)$ & $1(0.96 \%)$ & $2(1.92 \%)$ \\
\hline Unexplained & & $1(0.96 \%)$ & $0(0 \%)$ & $1(0.96 \%)$ \\
\hline
\end{tabular}

* IBS (C) Predominantly constipating * IBS (A) Diarrhoea alternating with constipation * IBS (D) Predominantly diarrhoeal 
Irritable bowel syndrome ranked second in order of frequency ( 24 cases $=23.08 \%$ ). It was more common in males than in females ( 9 cases $=37.5 \%$ ) with a male and female ratio was 1.67:1. Predominantly constipating type was more common (15 cases $=62.5 \%)$ than predominantly diarrhoeal form (2 cases $=8.33 \%$ ) (Table V). Seven cases (29.17\%) had diarrhoea alternating with constipation.

Table-V

Peptic ulcer disease $(n=36)$

\begin{tabular}{lcc}
\hline & Duodenal ulcer & Gastric ulcer \\
\hline Number of patients & $26(25 \%)$ & $10(9.62 \%)$ \\
Mean age (years) & 36.50 & 45.16 \\
Sex ratio (M F) & $3.33: 1$ & $1.5: 1$ \\
Duration of symptoms & 6.5 & 4.31 \\
in years (mean) & & \\
Number of smokers & $14(53.85 \%)$ & $4(40 \%)$ \\
Positive family history & $15(5769 \%)$ & $1(10 \%)$ \\
\hline
\end{tabular}

Non ulcer dyspepsia were third (22 cases $=21.15 \%$ ) common cause of upper abdominal pain. It was more common in females ( 12 cases $=54.55 \%$ ) than in males ( 10 cases $=45.45 \%$ ). Male and female ratio was 1:1.2. Twenty one patients (95.46\%) had ulcer like symptoms and one had (4.54\%) dysmotility like dyspepsia (Table VI).

Table-VI

Patients admitted with irritable bowel syndrome $(n=24)$

\begin{tabular}{lc}
\hline Irritable bowel syndrome & Data \\
\hline Total number of patients & $24(23.08 \%)$ \\
Mean age in years & 30.43 \\
Male and female ratio (M:F) 15:9 & $1.67: 1$ \\
Predominantly constipating type & $15(62.5 \%)$ \\
Diarrhoea alternating with constipation & $7(29.17 \%)$ \\
Predominantly diarrhoea! Type & $2(8.33 \%)$ \\
Duration of symptoms in years (mean) & 7.21 \\
\hline
\end{tabular}

In five subjects (4.81\%) with proved helminthiasis upper abdominal pain was relieved by administration of antihelmintic. Ova of ascaris lumbricoides were found in their stools. Among the rest of 99 subjects in the study, 21 had ova of ascaris lumbricoides, 27 had ova of entero-bius vermicularis, 5 had ova of hook worm and 2 had mixed infestations.
Table-VII

Patients admitted with non-ulcer dyspepsia $(n=22)$

\begin{tabular}{lc}
\hline Irritable bowel syndrome & Data \\
\hline Total number of patients & $22(21.15 \%)$ \\
Mean age in years & 29.62 \\
Male and femaleratio(M:F 10:12) & $1: 1.2$ \\
Ulcer like symptoms (Moynihan's) & $21(95.46 \%)$ \\
Dysmotility- like dyspepsia & $1(4.54 \%)$ \\
Duration of symptoms in years (mean) & 5.89 \\
\hline
\end{tabular}

Four subjects (3.85\%) had cholelithiasis. Three patients were female and one was male.

Four patients (3.85\%) were diagnosed as gastric carcinoma proved by histological examination of endoscopically obtained biopsy specimens from the lesion. Out of 4 patients three were male and one was female. All of them were aged patient ( $>50$ years) and presented with features of gastric outlet obstruction and severe anaemia along with upper abdominal pain.

Four patients (3.85\%) had amoebic liver abscess, three patients were male and one female. All of them had past history of amoebic dysentery.

Chronic pancreatitis was diagnosed in three (2.88\%) subjects of the study. Two patients were female and one was male and all of them had chronic calcific pancreatitis. One male patient had also diabetes mellitus.

One male patient $(0.96 \%)$ had acute pancreatitis. He had history of chronic alcohol intake.

In one subject, the cause of upper abdominal pain could not be defined. 8 subjects had combination of diseases, 6 subjects had PUD with IBS, 1 subject had PUD with ascariasis, and 1 had PUD with cholelithiasis.

Out of 100 patients presented with upper abdominal pain, 92patients (90.38\%) were diagnosed as peptic ulcer disease clinically at first interview with patients. Among them 46 patients were male and 46 female. Subsequently, investigations showed that 36 patients (34.62\%) had endoscopically proved peptic ulcer disease. 58 patients were misdiagnosed as peptic ulcer disease. There was significant discrepancy ( 56 cases=6 1.70\%) between clinically diagnosed and endoscopically diagnosed peptic ulcer disease (Table VII). Endoscopy of upper gastrointestinal tract was also done in patients who were not clinically diagnosed as PUD. Of them none had PUD. 
Table-VIII

Discrepancy between clinically diagnosed and endoscopically proved peptic ulcer disease $(n=94)$.

\begin{tabular}{lc}
\hline Peptic ulcer disease & Data \\
\hline Clinical diagnosed cases of PUD & $\begin{array}{c}92(90.38 \%) \\
\text { (of total 100patients) }\end{array}$ \\
$\begin{array}{l}\text { Male and female ratio of clinically } \\
\text { diagnosed PUD (M:F) }\end{array}$ & $1: 1.04$ \\
Endoscopically proved PUD & 36(34.62\%) \\
(of total 104 patient)
\end{tabular}

Table-IX

Presentation of endoscopicálly proven cases of PUD.

\begin{tabular}{|c|c|c|}
\hline & \multicolumn{2}{|c|}{ Duodenal ulcer Gastric ulcer } \\
\hline & $(n=26)$ & $(n=10)$ \\
\hline Upper abdominal pain & $26(100 \%)$ & $10(100 \%)$ \\
\hline Heart burn & $22(84.62 \%)$ & $4(40 \%)$ \\
\hline Nausea,Vomiting & $12(46.16 \%)$ & $10(100 \%)$ \\
\hline \multicolumn{3}{|l|}{ melaena } \\
\hline History of haematemesis and/or & $8(30.77 \%)$ & $3(30 \%)$ \\
\hline Epigastric tenderness & $24(92.30 \%)$ & $9(90 \%)$ \\
\hline Pointing sign & $20(76.92 \%)$ & - \\
\hline \multirow[t]{2}{*}{ Relief by food and/or antacid } & $21 / 23$ & $1 / 7$ \\
\hline & $(80.77 / 88.46 \%)$ & $(10 \% / 76 \%)$ \\
\hline Aggravation by food & $2(7.69 \%)$ & $6(60 \%)$ \\
\hline Periodicity & 25 (96.15\%) & - \\
\hline Nocturnal pain & $20(76.92 \%)$ & - \\
\hline History of taking NSAJDS & $9(34.62 \%)$ & $4(40 \%)$ \\
\hline History of smoking & $14(53.85 \%)$ & $4(40 \%)$ \\
\hline
\end{tabular}

Table IX shows presenting features of endoscopically proven PUD. Majority of patients with duodenal ulcer had heart burn, epigastric tenderness, positive pointing sign, periodicity and nocturnal pain. Majority of patient with gastric ulcer had epigastric tenderness and food aggravated their pain. ${ }^{6}$

\section{Discussion:}

This study was undertaken to assess the frequency of patients getting admitted with upper abdominal pain, aetiological patterns of upper abdominal pain, frequency of endoscopically confirmed peptic ulcer disease as a cause of upper abdominal pain, and discrepancy between clinically diagnosed and endoscopically proven peptic ulcer disease in medicine units of medical college hospital. Selections of patients for the study were made randomly on the basis of upper abdominal pain irrespective of age and sex. In this prospective study, some investigations are done routinely for all patients, particularly emphasizing on endoscopy of upper gastrointestinal tract and ultrasonogram of the whole abdomen. Only the patient having endoscopically confirmed ulcer/ulcers in the stomach or duodenum were leveled as PUD.

In the present series, $45.19 \%$ of subjects had no organic disease with a male and female ratio of 1.14:1. Among the patients getting admitted in medicine units of medical college hospital, 5.19\% patients were presented with upper abdominal pain, in whom $60.50 \%$ were male and $39.42 \%$ female.

Quite a good number of diseases could be diagnosed in subjects presented with upper abdominal pain. Peptic ulcer disease topped of the list. This was also the commonest organic case. $34.62 \%$ had peptic ulcer disease. It was more prevalent in males with male and female ratio of 2.6:1. ${ }^{7}$ Among the patients with PUD, $72.22 \%$ had duodenal ulcer and 27.78\% had gastric ulcer. Male and female ratio in cases of duodenal and gastric ulcer was 3.33:1 and 1.5:1 respectively. It appeared that the diagnosis of PU may be reasonably excluded when periodicity, relief of pain by food or antacids, pointing sign or epigastric tenderness were absent. However, they may occur in patient without PU (low specificity). Aggravation of pain by food intake was more common, as reported by other workers. $8,9,10$

It appears that positive diagnosis of PU cannot be made by the presence of individual symptoms. Sensitivity of pointing sign and epigastric tenderness is low because both can be present in PU, IBS and NTJD, a fact that indicating that they are of little value in distinguishing among these diseases. The mean ages of the patients were 36.50 years and 45.6 years in case of duodenal ulcer and gastric ulcer respectively. This age incidence correlates with common age of peptic ulcer disease as shown by various worker's. ${ }^{11}$ Sheppared et al. ${ }^{12}$ in 1987 showed higher age incidence in Western People. The ratio between duodenal ulcer and gastric ulcer was 2.6:1 which is similar in Western World. In United Kingdom it was 2.3:1. In Indian population it was higher 12.13:1. ${ }^{13,14}$ The much lower ratio in this series may possibly be explained by the correct localization of the ulcer after recent advancement of diagnostic technique i.e. by direct visualization of the ulcer point through a fibre optic endoscope.

Irritable bowel syndrome ranked second in order of frequency (23 08\%) IBS was more common in male with male and female ratio of 1.67:1. Predominantly constipating type was more common (62.5\%). Among the non-organic causes of upper 
abdominal pain, IBS topped the list representing 23.08\%. In the Western societies IBS is the commonest gastrointestinal syndrome. ${ }^{15,16,17}$ IBS patients also complained of nocturnal pain. ${ }^{9,11}$ Mean age of presentation of IBS was 30.43 years. It is consistent with the usual age of presentation of IBS. In studies of different workers ${ }^{18}$ IBS was more common in young female patients. ${ }^{19}$ The higher frequency in male in this series may, probably explained by the fact that the most female patients with mild upper abdominal pain and altered bowel habits do not get admitted in hospital.

In this series, NUD was common cause after PUD and IBS. $21.15 \%$ subjects had NUD with male and female ratio of 1:1.2 NUD is at least twice as common as PUD. ${ }^{20}$ But in the present series it ranked third in order of frequency after PUD and IBS. This discrepancy may probably be explained by the fact that most patients with dyspeptic symptoms do not get admitted in hospital but consult with local doctors or treated themselves by self-medication. The mean age of presentation was 29.62 which is consistent with usual presentation of NUD according to most workers. ${ }^{21}$ Female predominance in incidence in this series is also consistent with other studies. ${ }^{22,23}$

Helminthiasis was found to be a cause of upper abdominal pain. $4.81 \%$ had helminthiasis. Helminthiasis is considered to be a common cause of upper abdominal pain in Africa. ${ }^{24}$

In this series some others causes of upper abdominal pain were identified including cholilithiasis (3.85\%), gastric carcinoma (3.85\%), liver abscess (3.85\%), chronic pancreatitis (2.88\%) and acute pancreatitis (0.96\%). In one subject, cause could not be identified.

PUD is the most common organic cause for recurrent dyspeptic symptoms in many countries. ${ }^{25,26}$ Most patients presenting with the symptoms suggestive of peptic ulcer could be correctly diagnosed solely on clinical basis was emphasized by Moynihan. 27,28

It should be noted that eight subjects had combination of diseases, usually combination of an organic disorder with a functional one.

Out of 104 patients presented with upper abdominal pain in this series, $90.38 \%$ were diagnosed clinically as peptic ulcer disease. Among them $34.62 \%$ had endoscopically proved peptic ulcer disease. There was significant discrepancy (61.70\%) between clinically diagnosed peptic ulcer disease and endoscopically confirmed peptic ulcer disease. These findings are consistent those of other workers. ${ }^{29,30,31}$

Moynehan emphasized only the clinical basis for the diagnosis of peptic ulcer, but in a recent series by Azad Khan et a. ${ }^{32,33}$ it was found that $80 \%$ of all patients referred with a clinical diagnosis of duodenal ulcer had no ulcer in the duodenum endoscopically. NUD patients had burning type of abdominal pain ${ }^{23}$. Colicky abdominal pain occurred in $17.31 \%$ of patients, of them (14.42\%) had IBS.

Upper abdominal pain localized to epigastrium were present in $48.08 \%$ of patients, and most of them (25.96\%) had PUD $^{6} .11 .54 \%$ patients presented with epigastric pain had $\mathrm{NUD}^{34}$.Simultaneous epigastric and right hypochondric pain occurred in $23.08 \%$ of patients and $21.15 \%$ of patients had periumbilical pain. Most of them (16.35\%) had IBS.

$75 \%$ of PUD patients had epigastric pain $70.83 \%$ of patients with IBS had periumbilical pain, 90.91\% patients with NUD had epigastric and/or right hypochondrial pain.

Nocturnal pain was predominantly associated with PUD (83.33\%). It was also experienced by $20.83 \%$ of patients with IBS. Majority of patients with IBS (62.5\%) developed pain after taking food. 6 1.11\% PUD patients developed pain in empty stomach. $37.5 \%$, 28.85\% and $24.04 \%$ of patients had pain in empty stomach, pain after meal and nocturnal pain respectively.

Food relieved pain in $61.11 \%$ and $81.82 \%$ of patients with PUD and NUD respectively. Pain subsided after taking antacids in $90.91 \%$ and $83.33 \%$ of patients with NUD and PUD respectively. ${ }^{35}$ Bowel movement relieved pain in all patients of IBS.

Food aggravated pain in 75\% of patients with IBS and gastric carcinoma. It also aggravated pain in 50\%, 33.33\% and 22.22\% of patients with cholelithiasis, chronic pancreatitis and PUD respectively.

Most of the patients (72.22\%) of peptic ulcer disease had epigastric tenderness. $62.5 \%$ and $36.36 \%$ of patients with IBS and NUD respectively had no abdominal tenderness. ${ }^{36,37,38}$

In endoscopicalled proved PUD patients, all of them had upper abdominal pain and 84.62\% had heart burn, 30.77\% had history of haematemesis and/or melaena, $92.30 \%$ had epigastic tenderness $76.92 \%$ had positive pointing sign, 96.15\% had periodicity, 76.92\% had nocturnal pain.

Pointing sign was also positive in $33.33 \%$ and $27.27 \%$ of patients with IBS and NUD.

\section{Conclusion:}

An attempt has been made to evaluate the patients with upper abdominal pain of various duration. Concrete conclusion could not be made after reviewing such small number of cases, as they are not the representative of the whole population of the country. Though there is some variation of age and sex incidence compared with Western 
studies, the result in some instances, e.g. symptomatology and physical signs correlates well with their results.

There can be no doubt that whatever the mode of presentation, it can be diagnosed both clinically and by investigations, and then the correct management of course, will definitely ameliorate the condition of the patient.

In conclusion, it may be asserted that majority of patients with upper abdominal pain do not have peptic ulcer. ${ }^{2}$ Functional gut disorders are common causes of upper abdominal pain. ${ }^{3} \mathrm{~A}$ hurried history taking and overemphasis upon physical signs will lead to erroneous inclusions of such cases in the category of peptic ulcer. ${ }^{4}$ A carefully taken history and its rational interpretation may help in diagnosis. Thus simple means like explanation, reassurance and dietary advices may save a lot of antacids, $\mathrm{H}_{2}$ blockers and proton pump inhibitors, in many cases. So much unnecessary use of money and drugs can be avoided.

\section{Conflict of Interest : None}

\section{References:}

1. Collin MJ, Loebenberg MJ. Basal gastric secretion in nonulcer dyspepsia with or without duodenitis. Dig Dis Science 1989; 34: 246.

2. Malagelada JR, Stanghellini V. Manometric evaluation of upper gut symptoms. Gastroenterology 1985; 88: 12231231.

3. Gabriele Bianchi Porro, Fabrizioparente.Nature of Non-ulcer dyspepsia and related conditions.Bailliers-ClinGastroenterol. 1995; 9(3): 549-62.

4. Talley NJ. Textbook of Gastroenterology, Second Edition, edited by Tadaka Yamada. JB Lippincott Company, Philadelphia, 1995.

5. Talley NJ, Cohn-Jones D, Koch KL, et al. Functional dyspepsia: a classification with guidelines for diagnosis and management. Gastroenterol Int 1991; 4: 145.

6. Haq SA, Rahman MM, Hossain A, Hossain MA, et al. Nonacute upper abdominal pain; Journal of Bangladesh College of physicians and surgeons 1992; 10(3): 7.

7. Islam M Nazrul. Clinical picture of endoscopically proven peptic ulcer in Bangladesh. Bang Med J 1982; 10:134.

8. Walkin son, 1960. Peptic ulcer incidence in sex.

9. Talley NJ, Phillips SF, Melton U, Wiltgen C, Zinsmeister AR. A Patient Questionnaire to Identify Bowel Disease, Ann int. Med 1981; 111: 671-4.

10. Talley NJ, Phillips SF, Bruce B, TwomeyCK, Zinsmeister AR, Melton U. Relation Among Personality and Symptoms in non- ulcer dyspepsia and the Irritable Bowel Syndrome Gastroenterology 1990; 99: 327-33.
11. Talley NJ, Phillips SF, Melton J, Mulvihill C, Wiltgen C, Zinsmeister AR. Diagnostic value of the Manning criteria in irritable bowel syndrome. Gut 1990; 31: 77-81.

12. Edwards, F.C. and Coghill, N. F. Clinical manifestations in patients with chronic atrophic gastritis, gastric ulcer, and duodenal ulcer. Quarterly, J of Med. 1963; 37: 337-60.

13. Sheppard MG, Holmes GKT, Cockel R. Clinical picture of peptic ulcer diagnosed endoscopically. Gut 1977; 18: 524.

14. Tovey, F. Peptic ulcer in India and Bangladesh. Gut.1979; 20: 329-347.

15. Malhotra, SL. Peptic ulcer in India and its aetiology: Gut 1973; 5: 555.

16. Harvey RF, SalihSY, Read AE. Organic and functional disorders in 2000 Gastroenterology outpatients. Lancet 1983: $632-4$.

17. Mollman KM, Bonnevie O, Gudmand-Hoyer E, Wulff MR. Nosography of X-ray negative dyspepsia. Scand J Gastroenterol 1976; 11: 193-7.

18. Moriarty KJ, Dawson AM. Functional abdominal pain; further evidence that whole gut is affected.Br. Med J (Clin Res) 1982; 284: 1670-2.

19. Manning AP, Thompson WG, Heaton KW, Morris AF. Towards positive diagnosis of the irritable bowel. Br Med J 1978; 2: 653-654.

20. Swarbrick ET, Hegarty JE, Bat L, Williams CB, Dawson AM. Site of pain from irritable bowel. Lancet 1980; 2: 443-6.

21. Talley NJ. Phillips SF. Non-ulcer dyspepsia: potential causes and pathophysiology. Ann of Internal Med. 1988; 108: 865-879.

22. Hausken T. Berstad A. Wide gastric antrum in patients with non ulcer dyspepsia. Effects of cisapride. Scand J Gastroenterol 1992; 305: 280-2.

23. Thompson WG. Non-ulcer dyspepsia. Can Med Assoc J 1984; 130: 565-9.

24. Bates S. Sjoden PO, Fellinus J, Nyrin O. Blocked and nonblocked acid secretion and reported pain in ulcer, non-ulcer dyspepsia, and normal subjects, Gastroenterology 1989; 97: 376 .

25. Holcombe C. Aetiology and management of dyspepsia in Africa. Tropical Doctor 1991; 21: 107-12.

26. James LA, George NS, John FM, Eric JS. Diagnosis of peptic ulcer.In: Bocus HL (editor), Gastroenterology, $4^{\text {th }}$ ed. Philadelphia: W. B. Saunders, 1985; 1060-115.

27. Bocus, HL. Clinical and diagnostic aspects of uncomplicated peptic ulcer.In Bocus, HL.ed, Gastroenterology, Philadelphia, W.B. Saunders 1976: 619-647. 
28. Moynihan BGA. Duodenal ulcer. Philadelphia, Saunders, 1912.

29. Moynihan BGA. On duodenal ulcer: with notes of 52 operations Lancet 1905; 1:340.

30. RottarJI. Gastric and duodenal ulcers are each may different diseases. Diag Dis Sci1981; 26:154.

31. Tarpila S. Samloff JM, Pikkarainein, et al. Endoscopic and clinical findings in first degree relatives of duodenal ulcer patients and control subjects. Sc J Gastroenterol 1982; 78: 147.

32. Talley NJ, Mc Neil D, Hayden A, et al. Prognosis of chronic unexplained dyspepsia. A prospective study of potential predictor variables in patients with endoscopically diagnosed non-ulcer dyspepsia. Gastroenterology 1987; 92: 1060.

33. Azad Khan AK, Hasan M, Shah M, Ali K. Peptic ulcer in Bangladesh- An endoscopic survey. Gut 1985; 16:1117.
34. Azad Khan AK, Alam MN, Mohsen AQM, Haq KM. Upper gastrointestinal endoscopy-experience in IPGMR, Bangladesh Med J 1982; 11(1):15.

35. Jorgensen LS, Banlokke L, Wamberg P. Non-ulcer dyspepsia, Aspects of pain. Scand J Gastroenterol 1985; 20:46.

36. Berstad A. Non-ulcer dyspepsia and gastritis-clinical aspects. Journal of physiology and pharmacology 1993; 44(3): $41-49$.

37. Talley NJ and Phillips SF. Non-ulcer dyspepsia: potential causes and pathophysiology. Annals of Intern Medicine.1988; 108: 865-879.

38. Talley NJ. Modem management of dyspepsia. Australia Family Physician 1996; 25(1): 47. 